\title{
PERSEPSI KARYAWAN TERHADAP SISTEM PELAPORAN KECELAKAAN KERJA DAN POTENSI BAHAYA DI PERTAMBANGAN BATUBARA PT. PUTRA KAJANG KALIMANTAN TIMUR
}

\author{
Muhammad Sultan ${ }^{1^{\star}}$, Emil Riza Putra ${ }^{2}$, Herry Farjam ${ }^{3}$ \\ ('Universitas Mulawarman Samarinda, ${ }^{1}$ Politeknik Pertanian Negeri Samarinda, \\ ${ }^{3}$ Universitas Widyagama Mahakam Samarinda)
}

\begin{abstract}
Work accidents in coal mining still occur frequently, so an accident reporting system is needed as an effort to prevent work accidents. This study aims to explain the perceptions of coal mining employees on the reporting system for work accidents and potential hazards. The research design was descriptive with a sample size of 55 people. Data collection was carried out using a questionnaire. Data were analyzed descriptively. As many as $67.3 \%$ of employees have positive perceptions and $32.7 \%$ of employees have negative perceptions of the work accident reporting system and potential hazards. There are $72.7 \%$ of employees consider it important to report accidents and potential hazards. It was found that $30.9 \%$ of employees had experienced work accidents and only $5.4 \%$ of them reported accidents. Employees consider a good accident reporting system, among others, digitally $84.6 \%$ and manually $9.1 \%$. As many as $90.9 \%$ of employees agree and $81.8 \%$ of employees are willing to report accidents and potential hazards if the company implements a digital-based reporting system. There are still employees who have negative perceptions of the work accident reporting system and potential hazards in coal mining. Therefore, efforts are needed to increase employee perceptions from negative to positive perceptions of the work accident reporting system and potential hazards in coal mining companies.
\end{abstract}

Keywords: work accident; reporting; coal mining

\begin{abstract}
Abstrak
Kecelakaan kerja di pertambangan batubara masih sering terjadi sehingga diperlukan sistem pelaporan kecelakaan sebagai salah satu upaya pencegahan kecelakaan kerja. Penelitian ini bertujuan menjelaskan persepsi karyawan pertambangan batubara terhadap sistem pelaporan kecelakaan kerja dan potensi bahaya. Desain penelitian secara deskriptif dengan jumlah sampel sebanyak 55 orang. Pengumpulan data dilakukan dengan menggunakan kuesioner. Data dianalisis secara deskriptif. Sebanyak 67,3 \% karyawan yang memiliki persepsi positif dan 32,7 \% karyawan yang persepsi negatif terhadap sistem pelaporan kecelakaan kerja dan potensi bahaya. Terdapat 72,7 \% karyawan menganggap penting melaporkan kecelakaan dan potensi bahaya. Ditemukan 30,9\% karyawan yang pernah mengalami kecelakaan kerja dan hanya 5,4 \% di antaranya melaporkan kecelakaan yang dialami. Karyawan menganggap sistem pelaporan kecelakaan yang baik antara lain berbasis digital 84,6 \% dan manual 9,1\%. Sebanyak 90,9\% karyawan setuju dan 81,8\% karyawan di antaranya bersedia melaporkan kecelakaan dan potensi bahaya jika perusahaan menerapkan sistem pelaporan berbasis digital. Masih ditemukan karyawan yang memiliki persepsi negatif terhadap sistem pelaporan kecelakaan kerja dan potensi bahaya di pertambangan batubara. Oleh karena itu, diperlukan upaya untuk meningkatkan persepsi karyawan dari negatif menjadi persepsi positif terhadap sistem pelaporan kecelakaan kerja dan potensi bahaya di perusahaan pertambangan batubara.
\end{abstract}

Kata kunci: Kecelakaan kerja; Pelaporan; Pertambangan Batubara 


\section{PENDAHULUAN}

Kecelakaan kerja merupakan kejadian yang dialami baik salah satu maupun semua komponen di tempat kerja atau perusahaan seperti karyawan, pengusaha, dan manajemen di tempat kerja atau perusahaan yang mengkibatkan kerugian secara langsung dan tidak langsung ${ }^{1}$. Hal ini berarti bahwa semua pihak yang terlibat di perusahaan memiliki peluang sama untuk mengalami kecelakaan kerja dan penyakit akibat kerja (selanjutnya digunakan kata kecelakaan kerja).

Pertambangan batubara merupakan salah satu industri dengan tingkat bahaya dan risiko tinggi terjadinya kecelakaan kerja $^{2}$. Frekuensi kecelakaan kerja yang terjadi di sektor pertambangan batubara menjadi salah satu penyebab kematian tertinggi yang berarti bahwa tingkat risiko penyebab kecelakaan kerja di pertambangan batubara pun sangat tinggi ${ }^{3}$. Data menunjukkan bahwa kecelakaan tambang yang terjadi tahun 2017-2019 di Indonesia baik kecelakaan ringan, berat, dan meninggal dunia masing-masing 167 kasus, 146 kasus, dan 158 kasus $^{4}$.

Beberapa jenis kecelakaan kerja yang dapat terjadi di pertambangan batubara antara lain ledakan dan kebakaran yang dapat menewaskan karyawan akibat kelalaian atau perilaku tidak aman ${ }^{5}$. Paparan debu batubara dan debu lingkungan dari aktivitas penambangan yang mengakibatkan gangguan pada pernapasan karyawan seperti gangguan fungsi paru ${ }^{6}$, obstruktif ${ }^{7}$, infeksi saluran pernapasan akut $^{8}$, pneumokoniosis ${ }^{9}$, dan gangguan pernapasan lainnya ${ }^{10}$. Kecelakaan kerja berupa terjepit, tergores, dan bahkan kehilangan sebagian anggota badan seperti jari tangan pada area workshop ${ }^{11}$. Selain itu, aktivitas saat pengangkutan dan lalu lintas karyawan di jalan pengangkutan batubara (hauling) juga dapat menyebabkan kecelakaan kerja seperti tabrakan yang dapat melukai dan menewaskan karyawan, kendaraan terbalik akibat kondisi jalan berlubang, berbelok, dan sempit ${ }^{12}$. Jenis kecelakaan lainnya seperti tertimbun, tertimpa, tersetrum, tenggelam, terjatuh ${ }^{4}$.

Banyaknya kerugian yang dialami akibat kecelakaan kerja di pertambangan batubara mendorong pihak pemerintah melakukan berbagai upaya pengendalian bahaya dan risiko kecelakaan kerja. Misalnya, dukungan Pemerintah Cina terhadap keselamatan tambang batubara yang terus meningkat berdampak signifikan pada penurunan angka kematian akibat kecelakaan kerja $^{13}$, akan tetapi kejadian kecelakaan kerja masih tetap terjadi ${ }^{14}$. Pemerintah Indonesia pun telah mengamanatkan dalam suatu kebijakan tentang penerapan sistem manajemen $\mathrm{K} 3(\mathrm{SMK} 3)^{15}$, yang bertujuan untuk mencegah dan mengurangi kecelakaan kerja dengan melibatkan unsur manajemen, pekerja dan atau serikat pekerja.

Pihak perusahaan pun telah melakukan upaya pengendalian bahaya dan risiko kecelakaan kerja, namun kejadiannya terus terjadi ${ }^{16}$. Berbagai faktor penyebab sehingga masih terjadi kecelakaan kerja di perusahaan antara lain permasalahan keselamatan dan 
kesehatan kerja (K3) belum menjadi prioritas, kepatuhan karyawan terhadap pentingnya keselamatan yang masih rendah, kelemahan manajemen dalam menerapkan $\mathrm{K} 3$, menciptakan lingkungan kerja yang aman masih diabaikan ${ }^{17}$.

Salah satu upaya pencegahan dan penanggulangan kecelakaan kerja di perusahaan yakni sistem pelaporan kecelakaan kerja dengan melibatkan unsur pekerja, pengusaha, dan pemerintah. Pengurus atau pengusaha wajib melaporkan setiap kecelakaan yang terjadi di tempat kerja yang dipimpinnya. Begitu pula dengan pekerja memiliki tanggung jawab melaporkan kecelakaan kerja yang dialami dan potensi bahaya yang ditemukan di tempat kerja. Pemerintah setempat melakukan pemeriksaan dan pengkajian kecelakaan berdasarkan laporan yang diterima dari pihak perusahaan dan selanjutnya dilakukan analisis kecelakaan beradasarkan Peraturan Menteri Tenaga Kerja No. 03 Tahun 1998 Tentang Tatacara Pelaporan dan Pemeriksaan Kecelakaan. Pelaporan kecelakaan dapat memberikan informasi tentang area dan karyawan yang berisiko mengalami kecelakaan sehingga dapat dilakukan upaya pencegahan yang tepat dan segera ${ }^{18}$.

Pelaporan kecelakaan kerja dan potensi bahaya yang dilakukan oleh karyawan di tempat kerja merupakan hal penting dalam mengidentifikasi penyebab kecelakaan kerja dan sekaligus dapat menjadi informasi dini dalam mencegah kecelakaan kerja serupa di masa mendatang ${ }^{19}$. Pentingnya pelaporan kecelakaan kerja dan potensi bahaya tersebut sehingga menjadi salah satu fokus perhatian perusahaan dengan tingkat risiko tinggi kecelakaan seperti di pertambangan batubara. Keberhasilan perusahaan dalam melakukan pencegahan kecelakaan kerja dan pengendalian bahaya bukan hanya menjadi tanggung jawab perusahaan dan pemerintah saja, tetapi juga partisipasi karyawan.

PT. Putra Kajang merupakan salah satu perusahaan pertambangan batubara yang beroperasi di Provinsi Kalimantan Timur. Sejak beroperasi, masih ditemukan karyawan yang tidak melaporkan kecelakaan kerja dan potensi bahaya yang terdapat di tempat kerja. Padahal, pihak perusahaan telah mengimbau kepada setiap karyawan agar melaporkan kecelakaan kerja yang dialami dan potensi bahaya yang ditemukan saat berada di tempat kerja. Salah satu faktor penyebab pekerja tidak melaporkan kecelakaan kerja dan potensi bahaya karena sistem pelaporan kecelakaan masih dilakukan secara manual, sehingga membutuhkan waktu untuk memperoleh form pelaporan kecelakaan dan menyulitkan pembuktian dokumentasi dalam menemukan kondisi dan perilaku pekerja yang tidak $\operatorname{aman}^{20}$.

Dukungan dan partisipasi karyawan yang baik merupakan hal penting dalam kegiatan investigasi kecelakaan kerja sehingga kecelakaan di pertambangan batubara dapat dicegah agar tidak terulang kembali di masa yang akan datang dan secara signifikan menurunkan angka kecelakaan kerja ${ }^{14}$. Berdasarkan hal tersebut, pentingnya dilakukan kajian tentang persepsi karyawan terhadap sistem pelaporan kecelakaan kerja dan potensi bahaya sebagai 
informasi penting dalam melakukan intervensi upaya pengendalian kecelakaan kerja di pertambangan batubara secara tepat dan berkelanjutan.

\section{METODE PENELITIAN}

Desain penelitian deskriptif untuk menjelaskan persepsi karyawan dalam sistem pelaporan kecelakaan kerja dan potensi bahaya di pertambangan batubara. Populasi dalam penelitian sebanyak 55 orang yang merupakan karyawan di PT. Putra Kajang Kalimantan Timur dan semua karyawan akan dijadikan sampel penelitian (total sampling) ${ }^{21}$. Pengumpulan data dilakukan dengan menggunakan instrumen kuesioner. Penelitian dilaksanakan pada bulan Januari-Februari 2021 di PT. Putra Kajang, Provinsi Kalimantan Timur. Variabel yang akan diteliti dalam penelitian ini adalah persepsi karyawan terhadap sistem pelaporan kecelakaan kerja dan potensi bahaya yang dinilai berdasarkan hasil perhitungan persentase jawaban karyawan dan disajikan dalam bentuk tabel dan narasi.

\section{HASIL PENELITIAN}

Variabel yang diteliti dalam penelitian ini adalah persepsi karyawan terhadap sistem pelaporan kecelakaan kerja dan potensi bahaya. Persepsi karyawan dikategorikan menjadi positif jika karyawan menganggap bahwa pelaporan kecelakaan kerja dan potensi bahaya itu baik dan penting untuk dilakukan, sebaliknya persepsi negatif jika karyawan menganggap bahwa pelaporan kecelakaan kerja dan potensi bahaya itu tidak penting dilakukan. Adapun data dan informasi yang berhasil diperoleh dari responden penelitian disajikan pada tabel 1 , tabel 2, dan tabel 3 di bawah ini.

\begin{tabular}{|c|c|c|c|}
\hline Persepsi karyawan & Kategori & $\mathrm{F}$ & $(\%)$ \\
\hline \multirow{2}{*}{$\begin{array}{l}\text { Persepsi terhadap sistem pelaporan } \\
\text { kecelakaan kerja dan potensi bahaya }\end{array}$} & Positif & 37 & 67,3 \\
\hline & Negatif & 18 & 32,7 \\
\hline \multirow{3}{*}{$\begin{array}{l}\text { Persepsi karyawan dalam melaporkan } \\
\text { kecelakaan }\end{array}$} & Penting & 40 & 72,7 \\
\hline & Kurang penting & 10 & 18,2 \\
\hline & Tidak penting & 5 & 9,1 \\
\hline \multirow{2}{*}{$\begin{array}{l}\text { Persepsi karyawan dalam melaporkan } \\
\text { potensi bahaya }\end{array}$} & Penting & 37 & 67,3 \\
\hline & $\begin{array}{l}\text { Kurang penting } \\
\text { Tidak penting }\end{array}$ & $\begin{array}{c}8 \\
10\end{array}$ & $\begin{array}{l}14,5 \\
18,2\end{array}$ \\
\hline
\end{tabular}

Pada tabel 1 menunjukkan sebanyak 67,3 \% karyawan yang memiliki persepsi positif dan $32,7 \%$ karyawan yang persepsi negatif terhadap sistem pelaporan kecelakaan kerja dan potensi bahaya. Terdapat $72,7 \%$ karyawan yang menganggap bahwa pentingnya melaporkan kecelakaan kerja yang terjadi di perusahaan baik yang dialami sendiri maupun 
kecelakaan dialami oleh rekan kerjanya. Masih terdapat 18,2 \% karyawan yang menyatakan bahwa kurang penting, dan 9,1 \% yang menganggap tidak penting melaporkan kecelakaan kerja. Sebanyak 67,3 \% karyawan yang menilai penting, 14,5 \% karyawan menyatakan kurang penting, dan 18,2 \% yang menganggap bahwa tidak penting melakukan pelaporan potensi bahaya dan risiko di tempat kerja.

\begin{tabular}{lccc}
$\begin{array}{l}\text { Tabel 2. Praktik karyawan dalam melaporkan kecelakaan kerja dan } \\
\text { potensi bahaya }\end{array}$ & \multicolumn{1}{l}{} \\
\hline Praktik karyawan dalam sistem pelaporan & Kategori & $\mathrm{F}$ & $(\%)$ \\
\hline Pernah mengalami kecelakaan & Pernah & 17 & 30,9 \\
& Tidak pernah & 38 & 69,1 \\
\hline Melaporkan kecelakaan yang dialami & Ya & 3 & 5,4 \\
& Tidak & 14 & 25,5 \\
\hline Melaporkan potensi bahaya & Ya & 12 & 21,8 \\
& Tidak & 43 & 78,2 \\
\hline Kepada siapa melaporkan kecelakaan & Teman & 1 & 1,8 \\
& Supervisor K3 & 1 & 1,8 \\
& Direksi/manager & 1 & 1,8 \\
& Tidak melapor & 14 & 25,5 \\
\hline
\end{tabular}

Tabel 2 menunjukkan bahwa karyawan yang pernah mengalami kecelakaan kerja selama bekerja sebanyak 30,9 \% karyawan. Karyawan yang melaporkan kecelakaan yang dialami sebanyak 5,4 \% karyawan dan 25,5 \% karyawan yang tidak melaporkan. Karyawan yang pernah melaporkan potensi bahaya dan risiko kecelakaan kerja sebanyak 21,8 \% karyawan dan 78,2 \% karyawan yang tidak melaporkan potensi bahaya kecelakaan. Karyawan yang mengalami kecelakaan kerja melaporkan kepada teman kerja, supervisor $\mathrm{K} 3$, dan kepada direksi/manager masing-masing 1,8\%.

Tabel 3. Persepsi karyawan tentang pelaporan kecelakaan kerja yang baik

\begin{tabular}{lccc}
\hline Persepsi karyawan tentang sistem pelaporan & Kategori & $\mathrm{F}$ & $(\%)$ \\
\hline Sistem pelaporan yang baik & Manual & 5 & 9,1 \\
& Digital & 46 & 84,6 \\
& Tidak tahu & 4 & 7,3 \\
\hline Pelaporan kecelakaan berbasis digital & Setuju & 50 & 90,9 \\
& Kurang setuju & 3 & 5,5 \\
& Tidak setuju & 2 & 3,6 \\
\hline Kesediaan melaporkan kecelakaan dan & Bersedia & 45 & 81,8 \\
potensi bahaya berbasis digital & & & \\
& Tidak bersedia & 5 & 9,1 \\
\hline
\end{tabular}

Tabel 3 menunjukkan bahwa karyawan yang menganggap sistem pelaporan kecelakaan kerja dan potensi bahaya yang baik antara lain secara manual 9,1\% karyawan dan digital 84,6 \%. Sebanyak 90,9 \% karyawan yang setuju, 5,5\% kurang setuju, dan 3,6\% karyawan yang tidak setuju jika di perusahaan tersebut diberlakukan sistem pelaporan kecelakaan kerja berbasis digital. Karyawan yang bersedia melaporkan kecelakaan kerja 
dan potensi bahaya berbasis digital jika sistem tersebut diterapkan dan sebanyak 81,8\% dan $9,1 \%$ karyawan yang tidak bersedia melakukannya.

\section{PEMBAHASAN}

Jumlah tenaga kerja Indonesia tercatat $65,7 \%$ dari populasi penduduk di Indonesia dan $22,4 \%$ di antaranya bekerja di sektor industri ${ }^{22}$. Salah satu sektor industri berisiko kecelakaan kerja adalah pertambangan batubara. Tenaga kerja yang mengalami kecelakaan kerja sektor pertambangan batubara tetap terjadi setiap tahun meskipun angkanya mengalami perubahan setiap tahunnya ${ }^{4}$. Hal ini berarti bahwa kecelakaan kerja di sektor industri pertambangan batubara masih menjadi permasalahan yang harus diperhatikan dan dikendalikan kejadiannya agar tenaga kerja tetap dalam kondisi sehat dan produktif.

Tahapan pertambangan batubara secara umum meliputi penyelidikan umum, eksplorasi, penambangan (eksploitasi), pengolahan, pemurnian, dan pengangkutan sebelum sampai dimanfaatkan oleh konsumen ${ }^{23}$. Pada setiap tahapan tersebut masih ditemukan seringkali terjadi kecelakaan kerja seperti tertimbun tanah saat pengupasan lahan permukaan, terjatuh dari ketinggian lahan dan terluka, tergores dan terpotong pada saat reparasi peralatan di workshop, terkilir hingga patah tulang, keluhan kesehatan berupa gangguan sistem pernapasan dan muskuloskeletal, tertabrak hingga meninggal dunia saat proses pengangkutan, dan berbagai risiko kecelakaan kerja lainnya.

Banyaknya bahaya dan risiko pada kegiatan usaha pertambangan batubara maka Pemerintah Indonesia membuat kebijakan yang mengatur tentang kewajiban perusahaan melaksanakan ketentuan keselamatan pertambangan dengan berbagai kegiatan antara lain program keselamatan kerja yang meliputi pencegahan dan penyelidikan kecelakaan, kebakaran, dan kejadian lain yang berbahaya ${ }^{24}$. Kegiatan pelaporan kecelakaan kerja merupakan salah satu upaya pencegahan dan penyelidikan kecelakaan kerja agar kejadian kecelakaan serupa dan bahkan mencegah tidak terjadinya kecelakaan telah diatur dalam Peraturan Menteri Tenaga Kerja Nomor 03 Tahun 1998 Tentang Tatacara Pelaporan dan Pemeriksaan Kecelakaan Kerja. Pelaksanaan sistem pelaporan kecelakaan kerja yang dilakukan di berbagai sektor industri seperti pertambangan batubara di Indonesia masih dilakukan secara manual ${ }^{20}$ sehingga ditemukan masih banyak kelemahan dalam penerapannya.

Pada penelitian ini menunjukkan bahwa sebagian besar karyawan mengatakan penting melaporkan kecelakaan dan potensi bahaya kecelakaan. Tampak bahwa terdapat kemauan karyawan untuk berpartisipasi dalam melaporkan setiap sumber bahaya dan risiko serta kecelakaan kerja yang terjadi di tempat kerja dan hal ini merupakan tanda positif jika dilakukan perbaikan dalam proses pelaporan kecelakaan kerja. Pelaporan yang meliputi 
kegiatan investigasi dan analisis kecelakaan kerja yang dilakukan berguna dalam identifikasi penyebab dan sekaligus sebagai informasi terkini sehingga kecelakaan kerja dapat dicegah sejak dini sebelum terjadi kecelakaan kerja ${ }^{19}$.

Sistem investigasi kecelakaan bertujuan mencegah kecelakaan kerja serupa agar tidak terulang kembali pada waktu yang akan datang. Akan tetapi, sistem investigasi yang masih berfokus menjawab dimana kecelakaan terjadi masih kurang efektif dalam mencegah kecelakaan sehingga diperlukan pengembangan metode investigasi dengan menjawab pertanyaan bagaimana agar tidak terjadi lagi kecelakaan kerja ${ }^{25}$. Segala keterbatasan sistem pelaporan yang ada saat ini (manual) perlu dialihkan menjadi sistem digital menggunakan perangkat teknologi yang tepat.

Peringatan secara dini dan prediksi risiko kecelakaan yang terjadi di pertambangan batubara berbasis multimedia merupakan salah satu langkah efektif untuk mencegah terjadinya kecelakaan seperti semburan gas, air, kebakaran dan semburan batu serta dapat mengurangi korban jiwa dan kerugian harta benda. Data yang berhasil dihimpun dari sistem pelaporan kecelakaan tambang batubara selanjutnya digunakan untuk peningkatan pemantauan faktor kecelakaan, mengurangi risiko kecelakaan dari sumbernya, dan meningkatkan tingkat manajemen keselamatan tambang batubara ${ }^{26}$. Sistem keamanan dan keselamatan pertambangan batubara merupakan hal penting untuk mencegah kecelakaan tambang yang dapat mengakibatkan banyaknya korban jiwa. Salah satu sistem yang dikenal adalah sistem pemantauan keselamatan penambang batubara secara digital untuk mendeteksi bahaya di lingkungan kerja dan menghubungkannya dengan karyawan serta unit pengendali agar segera dilakukan upaya pengendalian bahaya ${ }^{27}$.

Kecelakaan pada kegiatan pengangkutan (hauling) batubara kerapkali terjadi dan mengakibatkan korban luka hingga meninggal dunia. Kerugian keuangan terbesar perusahaan tambang batubara akibat kecelakaan kerja adalah aktivitas hauling batubara dari area penambangan ke pelabuhan ${ }^{28}$. Pengalaman di Kolombia pada sektor perhubungan yang banyak menelan korban meninggal dunia akibat kecelakaan lalu lintas dilakukan penerapan teknologi aplikasi perangkat lunak dan hasilnya menunjukkan bahwa sistem ini secara siginifikan meningkatkan kecepatan waktu pencatatan informasi dan keandalan laporan kecelakaan sehingga dapat digunakan dalam pengambilan keputusan yang tepat dalam mencegah kecelakaan ${ }^{29}$. Begitu pula jika diperlukan tindakan lanjutan seperti pengiriman kendaraan ambulans saat terjadi kecelakaan secara cepat dan tepat sesuai laporan kecelakaan melalui sistem peringatan menggunakan aplikasi perangkat lunak ${ }^{30}$.

Pengalaman Palang Merah Indonesia Kota Malang dalam penanganan kecelakaan, kedaruratan medis, dan mengevakuasi korban saat terjadi musibah seringkali mengalami kendala sehingga mengembangkan sistem pelaporan menggunakan aplikasi emergency button yang dinamakan Scrum dan terbukti bahwa tingkat partisipasi pemakai mencapai 70- 
$100 \%{ }^{31}$. Hal ini dapat dijadikan referensi dalam menerapkan sistem pelaporan secara digital di perusahaan pertambangan batubara. Selain itu, antusias karyawan di pertambangan batubara juga tampak setuju dan bersedia melaporkan kecelakaan kerja dan potensi bahaya di tempat kerja menggunakan sistem pelaporan secara digital atau elektronik.

Pemanfaatan sistem informasi digital bukan hanya dikembangkan di sektor industri pertambangan batubara, di industri keselamatan penerbangan juga telah memanfaatkan sistem digital dan terbukti dapat menurunkan sekitar $20 \%$ kejadian kecelakaan di dunia penerbangan setiap tahunnya ${ }^{32}$. Hal ini menjadi angin segar di sektor usaha pertambangan batubara bahwa penerapan sistem digital dapat menekan dan mengurangi angka kecelakaan kerja yang terjadi. Selain itu, dukungan dari karyawan di PT. Putra Kajang, Provinsi Kalimantan Timur yang menyatakan bahwa mereka setuju dan bersedia melakukan pelaporan kecelakaan dan potensi bahaya kecelakaan kerja berbasis digital.

Penerapan sistem pelaporan secara digital tentu diperlukan komitmen perusahaan dalam menerapkannya seperti dukungan kebijakan dan pembiayaan dalam penyediaan perangkat lunak. Selain itu, dibutuhkan partisipasi karyawan dalam melaporkan kecelakaan kerja dan potensi bahaya serta melek teknologi. Partisipasi semua komponen di tempat kerja yakni karyawan atau serikat pekerja, pengusaha atau manajemen perusahaan, dan pemerintah sangatlah penting dalam pencegahan dan pengendalian kecelakaan kerja.

\section{SIMPULAN DAN SARAN}

Karyawan perusahaan pertambangan batubara sebagian besar memiliki persepsi positif dibandingkan karyawan yang berpersepsi negatif terhadap sistem pelaporan kecelakaan kerja dan potensi bahaya. Masih ditemukan karyawan yang menganggap bahwa pelaporan kecelakaan kerja dan potensi bahaya di tempat kerja merupakan hal yang tidak penting dilakukan. Selain itu, masih ditemukan juga karyawan yang tidak melaporkan kecelakaan saat mengalami kecelakaan kerja dan tidak melaporkan potensi bahaya yang terdapat di tempat kerja. Oleh karena itu, diperlukan upaya untuk meningkatkan persepsi positif bagi karyawan terhadap sistem pelaporan kecelakaan kerja dan potensi bahaya di perusahaan pertambangan batubara agar dapat mencegah kecelakaan serupa tidak terulang lagi di masa yang akan datang.

\section{DAFTAR PUSTAKA}

1. Sultan, M. Kecelakaan Kerja; Mengapa Masih Terjadi di Tempat Kerja ? (Uwais Inspirasi Indonesia, 2020).

2. Mega, G. W. K. KESEHATAN DAN KESELAMATAN KERJA (K3) PADA PERTAMBANGAN BATUBARA DI PT. MARUNDA GRAHAMINERAL, JOB SITE LAUNG TUHUP KALIMANTAN TENGAH. J. Chem. Inf. Model. (2016). 
3. Khamidullina, E. A., Timofeeva, S. S. \& Smirnov, G. I. Accidents in Coal Mining from Perspective of Risk Theory. in IOP Conference Series: Materials Science and Engineering (2017). doi:10.1088/1757-899X/262/1/012210.

4. Direktorat Jenderal Mineral dan Batubara \& Mineral, K. E. dan S. D. Minerba Dalam Angka Tahun 2017-2019. (2020).

5. Tong, R. et al. Risk assessment of Miners' unsafe behaviors: A case study of gas explosion accidents in coal mine, china. Int. J. Environ. Res. Public Health (2019) doi:10.3390/ijerph16101765.

6. Simanjuntak, Nelly Sri rahayu; Suwondo, Ari; Wahyuni, I. Hubungan Antara Kadar Debu Batubara Total Dan Terhirup Serta Karakteristik Individu Dengan Gangguan Fungsi Paru Pada Pekerja Di Lokasi Coal Yard Pltu X Jepara. J. Kesehat. Masy. Univ. Diponegoro (2013).

7. Sugiharti, S. \& Sondari, T. R. GAMBARAN PENYAKIT PARU OBSTRUKTIF KRONIK (PPOK) DI DAERAH PERTAMBANGAN BATUBARA, KABUPATEN MUARA ENIM, PROVINSI SUMATERA SELATAN. J. Ekol. Kesehat. (2016) doi:10.22435/jek.v14i2.4668.136-144.

8. Hafsari, D., Ramadhian, M. R. \& Saftarina, F. Debu Batu Bara Dan Kejadian Infeksi Saluran Pernafasan Akut Pada Pekerja Pertambangan Batu Bara. Majority (2015).

9. Kesehatan, K. \& Indonesia, R. Pekerja industri pertambangan rentan terkena pneumoconiosis. Kementeri. Kesehat. RI (2017).

10. Sinaga, N. N. P., Hutagalung, P. \& Andriana, J. WASPADA PNEUMOKONIOSIS PADA PEKERJA DI INDUSTRI PERTAMBANGAN. J. Kedokt. (2020).

11. Putri, R. R. Analisis Potensi Bahaya Serta Rekomendasi Perbaikan Dengan Metode Hazard and Operability Study ( Hazops ) Studi Kasus PT. Bukt Asam Tbk. Universitas Diponegoro (2018).

12. Mustofa, A., Akbar, B. M., Nurhakim, N. \& Sariffudin, S. ANALISIS PENGARUH TINGKAT PELAYANAN JALAN TERHADAP KESELAMATAN KERJA PADA TAMBANG BATUBARA. J. Himasapta (2019) doi:10.20527/jhs.v1i03.933.

13. Jiang, F. chuan, Lai, E., Shan, Y. xuan, Tang, F. hao \& Li, H. gang. A set theory-based model for safety investment and accident control in coal mines. Process Saf. Environ. Prot. (2020) doi:10.1016/j.psep.2020.02.003.

14. Liu, R., Cheng, W., Yu, Y. \& Xu, Q. Human factors analysis of major coal mine accidents in China based on the HFACS-CM model and AHP method. Int. J. Ind. Ergon. (2018) doi:10.1016/j.ergon.2018.08.009.

15. PP No 50 TAHUN 2012. Sistem Manajemen K3. SMK3 (2012).

16. Hamdy, M. I. Analisa Potensi Bahaya dan Upaya Pengendalian Kecelakaan Kerja Pada Proses Penambangan Batu Adesit di PT. Dempo Bangun Mitra. J. Tek. Ind. J. Has. 
Penelit. dan Karya IIm. dalam Bid. Tek. Ind. (2016) doi:10.24014/jti.v2i2.5101.

17. Zhang, J. et al. Root causes of coal mine accidents: Characteristics of safety culture deficiencies based on accident statistics. Process Saf. Environ. Prot. (2020) doi:10.1016/j.psep.2020.01.024.

18. Smith, P. M. et al. The development of a conceptual model and self-reported measure of occupational health and safety vulnerability. Accid. Anal. Prev. (2015) doi:10.1016/j.aap.2015.06.004.

19. Qiao, W., Li, X. \& Liu, Q. Systemic approaches to incident analysis in coal mines: Comparison of the STAMP, FRAM and "2-4" models. Resour. Policy (2019) doi:10.1016/j.resourpol.2019.101453.

20. Sinaga, B. R., Werdana, K. P., Irwanto, D. \& Hanafi, N. PENGGUNAAN APLIKASI ISAFE DALAM PENERAPAN KESELAMATAN PERTAMBANGAN PT. BORNEO INDOBARA KALIMANTAN SELATAN. Pros. Temu Profesi Tah. PERHAPI (2020) doi:10.36986/ptptp.v1i1.108.

21. Sugiyono. Metode Penelitian Kuantitatif Kualitatif dan RD. Alfabeta (2017).

22. ILO. ILO Data Explorer. ILO Data Explor. 5-6 (2020).

23. Universitas Prof Dr Moestopo. Teknik pertambangan. 1-13.

24. Menteri ESDM RI. Peraturan Menteri ESDM Nomor 26 Tahun 2018 tentang Pelaksanaan Kaidah Pertambangan yang Baik dan Pengawasan Pertambangan Mineral dan Batubara. (2018).

25. Dash, A. K., Bhattacharjee, R. M., Ahmad, A., Sagesh, K. M. R. \& Singh, C. S. Mine accident investigation in India: A system approach. J. Mines, Met. Fuels (2018).

26. Huang, Y. \& Zhou, Q. Mine accident prediction and analysis based on multimedia big data. Multimed. Tools Appl. (2019) doi:10.1007/s11042-019-7175-6.

27. Shareef, S. K., Anand Kumar, B., Suwarna, G. \& Swathi, M. Coal miners safety monitoring system. Int. J. Innov. Technol. Explor. Eng. (2019) doi:10.35940/ijitee.L3246.1081219.

28. Adyatama, A., Syaifullah, D. H. \& Moch, B. N. Evaluating the role of cognitive factors on hauling workplace accidents: Study case at Central Borneo coal mining company. in AIP Conference Proceedings (2020). doi:10.1063/5.0007247.

29. Smith Florez-Moreno, D., Felipe Reyes-Contreras, C., Eduardo Villamizar-Camelo, S. \& Andres Zabala-Vargas, S. Prototype of technological tool for the registration, storage, transmission and analysis of traffic accident information. Rev. ITECKNE (2018).

30. Goldin, S. E. \& Rudahl, K. T. Crowdsourced Traffic Accident Reporting for Hot Spot Analysis and Emergency Response. DEStech Trans. Eng. Technol. Res. (2017) doi:10.12783/dtetr/ictim2016/5542.

31. Lia Farokhah, Fadhli Almu'ini Ahda \& Lukman Hakim. Implementasi SCRUM dalam 
Perancangan Aplikasi Emergency Button PMI Kota Malang. Digit. Zo. J. Teknol. Inf. dan Komun. (2020) doi:10.31849/digitalzone.v11i1.3869.

32. Burns, K., Bonaceto, C., Estes, S. \& Helleberg, J. Evaluating the operational safety of a digital copilot. in AAAI Fall Symposium - Technical Report (2017). 